\title{
Clinical Outcomes After Second-Generation Trabecular Microbypass Stents (iStent inject@) with Phacoemulsification in Korean Patients
}

\author{
Seungsoo Rho $\cdot$ Su-Ho Lim (1D
}

Received: September 15, 2021 / Accepted: October 7, 2021 / Published online: October 26, 2021

(c) The Author(s) 2021

\begin{abstract}
Introduction: To evaluate the intraocular pressure (IOP)-lowering effect of second-generation trabecular microbypass stents (iStent ${ }^{\circledR}$ inject) with cataract extraction (combination group) and compare refractive changes in the combination group and the control (phacoemulsification only) group.

Methods: This retrospective case-control study included 36 eyes with cataract and medically controlled open-angle glaucoma with IOP $<21 \mathrm{mmHg}$ and 100 nonglaucomatous eyes with cataract. Data were collected preoperatively and for 6 months postoperatively. Data included IOP, number of glaucoma medications, corrected distance visual acuity, and mean absolute error (MAE) from target refraction, and astigmatic vector analysis. Surgical success for the combination group was defined according to three criteria: (A) IOP $<15 \mathrm{mmHg}$ without medication, (B) IOP $<18 \mathrm{mmHg}$
\end{abstract}

S. Rho

Department of Ophthalmology, CHA Bundang

Medical Center, CHA University, Seongnam, South

Korea

S.-H. Lim $(\bowtie)$

Department of Ophthalmology, Daegu Veterans

Health Service Medical Center, \#60 Wolgok-Ro,

Dalseo-Gu, Daegu 42835, South Korea

e-mail: mdshlim@gmail.com without medication, and (C) IOP $<18 \mathrm{mmHg}$ with or without medication.

Results: In the combination group, mean IOP was reduced from $15.1 \pm 2.9 \mathrm{mmHg}$ to $12.5 \pm 2.0 \mathrm{mmHg}$, and the mean number of medications decreased from $1.9 \pm 1.0$ to $0.4 \pm 0.8$ at postoperative 6 months (both $P<0.001)$. Surgical success rates were $77.8 \%$, $83.3 \%$, and $97.2 \%$ at 6 months by criteria A, B, and $\mathrm{C}$, respectively. Mean IOP was reduced from $14.3 \pm 2.7 \mathrm{mmHg}$ to $13.1 \pm 2.1 \mathrm{mmHg}$ at 1 month in the control group $(P<0.001)$. The MAE was $0.33 \pm 0.26 \mathrm{D}$, and $83.3 \%$ of eyes had spherical equivalent difference within $0.50 \mathrm{D}$ in the combination group $(0.38 \pm 0.33 \mathrm{D}$ and $76.0 \%$ in the control group; $P=0.309$ and $P=0.363$, respectively). Preoperative and postoperative centroid values were $0.51 \mathrm{D} @ 1^{\circ}$ and $0.66 \mathrm{D} @ 178^{\circ}$, respectively $\left(0.23 \mathrm{D} @ 176^{\circ}\right.$ and $0.66 \mathrm{D} @ 1^{\circ}$ in the control group). There were no statistical differences between the two groups with respect to preoperative and postoperative mean absolute values $(P=0.154$ and $P=0.322$, respectively).

Conclusions: On the basis of our results using Korean real-world interim experience, iStent ${ }^{\circledR}$ inject with cataract extraction has favorable IOP-lowering effects and minimally impacts refractive outcomes. 
Keywords: Cataract; Glaucoma; Intraocular Pressure (IOP); iStent Inject; MIGS; Refractive Outcome

\section{Key Summary Points}

Although many previous studies have demonstrated favorable efficacy of second-generation trabecular microbypass stents (iStent ${ }^{\circledR}$ inject) in patients with high intraocular pressure (IOP), there have been no published studies in Korean patients.

Moreover, few studies comparing refractive outcomes after iStent ${ }^{\circledR}$ inject with cataract surgery (combination procedure) to cataract surgery alone have been conducted.

At the 6-month follow-up, $77.8 \%$ of eyes had IOP $<15 \mathrm{mmHg}$ without medication, $83.3 \%$ of eyes had IOP $<18 \mathrm{mmHg}$ without medication, and $83.3 \%$ of eyes were medication-free (vs. mean 1.9 medications preoperatively).

The mean absolute error was $0.33 \pm 0.26 \mathrm{D}$, and $83.3 \%$ of eyes had spherical equivalent difference within $0.5 \mathrm{D}$.

Trabecular microbypass stent (iStent ${ }^{\circledR}$ inject) with cataract extraction affords beneficial reductions in IOP and glaucoma medications and excellent refractive outcomes without severe refractive surprise in our interim experience in Korea.

\section{INTRODUCTION}

Glaucoma is one of the leading causes of blindness worldwide [1]. Many randomized clinical trials have demonstrated that intraocular pressure (IOP) is the primary modifiable risk factor for "diagnosis" and "disease progression" of glaucoma [2-4]. Thus, the focus of glaucoma treatment aims to reduce IOP, which is the only treatment strategy proven to reduce its progression $[2,4-6]$.

Although standard glaucoma surgeries, including trabeculectomy and glaucoma drainage devices (GDD), have favorable IOP-lowering efficacy, they also have risks of serious vision-threatening complications including hypotony, inflammation, bleb-related complications, and loss of vision $[5,7]$. The goal of glaucoma treatment is to maintain visual function and quality of life at a sustainable cost [8]. In this context, the number of micro-invasive glaucoma surgery (MIGS) procedures has increased because they offer safer interventional glaucoma treatment earlier in the course of the disease [6, 9-11]. In particular, canal-based MIGS provides advantages such as quicker visual recovery and sparing of conjunctival tissue for future glaucoma surgeries [10, 12-14].

The single trabecular microbypass stent with an internal diameter of $120 \mu \mathrm{m}$ (iStent ${ }^{\circledR}$ ) and the second-generation iStent ${ }^{\circledR}$ inject (containing two stents, each with an internal diameter of $80 \mu \mathrm{m})$ were designed to allow direct aqueous flow into Schlemm's canal, bypassing the trabecular meshwork $[12,13]$. Both devices have been studied in a variety of surgical treatment approaches, including stand-alone and cataract combination treatment; with single or multiple stents; and in the spectrum of glaucoma severities from mild to advanged stages, or even failed trabeculectomy [12, 15-19]. Although many previous studies have demonstrated favorable efficacy in patients with uncontrolled IOP or high IOP, studies in patients with normal tension glaucoma are limited $[13,14]$ and no studies have been published on second-generation trabecular microbypass stents in Korean eyes [15]. In addition, many studies with conventional glaucoma surgeries, such as trabeculectomy and glaucoma drainage device surgery, have shown decreased axial length, significant astigmatic changes, and increased refractive surprise [20-22]. Few studies, however, focused on refractive outcomes after phaco-combined surgery using iStent ${ }^{\circledR}$ or iStent ${ }^{\circledR}$ inject (combination group) $[9,23]$.

The purposes of this study are (1) to analyze IOP-lowering effects after combination 
procedures in primary open-angle glaucoma (POAG) and (2) to analyze and compare refractive outcomes between combination procedures in a glaucoma group and phaco-only procedures in a control group without glaucoma.

\section{METHODS}

\section{Patients}

This was a single-center, retrospective, case control study conducted at Daegu Veterans Health Service Medical Center. This comparative study on refractive outcomes consisted of 36 patients undergoing second-generation trabecular microbypass stent with phacoemulsification and 100 nonglaucomatous patients who underwent cataract surgery only from September 2020 to January 2021. The study protocol was approved by the Institutional Review Board of Daegu Veterans Health Service Medical Center. All participants provided signed informed consent. The study adhered to the tenets of the Declaration of Helsinki. The inclusion and exclusion criteria were similar to those in our previous study [17].

Inclusion criteria for the combination group were (1) IOP $<21 \mathrm{mmHg}$ with anti-glaucoma medications, (2) presence of cataract, and (3) need for additional reduction of IOP (poor compliance, drug allergy, or disease progression despite use of ocular hypotensive medications). The first eye undergoing the procedure was chosen for cases of bilateral disease. The cataract surgery control group included 100 consecutive eyes without severe ocular disease, such as glaucoma, macular degeneration, or ocular surface diseases, and that underwent phacoemulsification cataract surgery.

Exclusion criteria for the combination group included (1) eyes with less than 6 months of follow-up, (2) patients who underwent another procedure at the same time, (3) angle-closure glaucoma or secondary glaucoma such as inflammatory glaucoma or neovascular glaucoma, or (4) history of previous glaucoma surgery, such as trabeculectomy or glaucoma drainage device implantation.

\section{Baseline Examination}

All patients underwent comprehensive ophthalmic examinations, including best corrected visual acuity, Goldmann applanation tonometry, gonioscopy, dilated fundus examination, and retinal nerve fiber layer (RNFL) measurement using spectral domain optical coherence tomography (SD-OCT; Cirrus6000, Zeiss, Jena, Germany). Automated perimetry was performed using a Humphrey Visual Field Analyzer (740i, 840, Carl Zeiss Meditec Inc., Dublin, CA).

Glaucomatous visual field defects were defined as follows: (1) those corresponding to the optic nerve head or RNFL changes; (2) glaucoma hemifield test (GHT) results outside of the normal limits; and (3) a cluster of three or more non-edge contiguous points not crossing the horizontal meridian, with $P$ value $<0.01$. The Hodapp-Anderson criterion was used to classify the severity of glaucoma [24].

Biometry was performed using an IOL Master 500 instrument (Zeiss, Jena, Germany). On the basis of surgeon choice, the SRK/T power calculation formula was used to determine the postoperative refraction target.

\section{Surgical Technique}

All surgeries were performed by a single glaucoma specialist (S.H.L.) who completed a wetlab training program and glaucoma fellowship. Briefly, under topical anesthesia, phacoemulsification was performed with a $2.4 \mathrm{~mm}$ keratome. A single-piece, hydrophobic, acrylate, intraocular lens was inserted in both groups. Then, trabecular microbypass stents (iStent ${ }^{\circledR}$ inject) were implanted after routine cataract procedures. The iStent ${ }^{\circledR}$ inject is comprised of two, preloaded, heparin-coated, biocompatible, titanium stents in a single-use injector. Each stent was inserted $a b$ interno through the nasal trabecular meshwork into Schlemm's canal using a Swan Jacob gonioprism. A second stent was placed 2-3 hours away from the first stent. The ophthalmic viscodevice (OVD) was removed, and the eye was filled with a balanced salt solution. 


\section{Postoperative Medications and Follow-up}

Postoperatively, topical $0.5 \%$ gatifloxacin and $0.1 \%$ fluorometholone acetate eye drops were prescribed four times daily for 1 week and then tapered according to the resolution of inflammation. Topical bromfenac $0.07 \%$ for 4 weeks also was prescribed.

Each patient's best corrected visual acuity (BCVA), IOP, number of anti-glaucoma medications, and complications were recorded at 1 day, 1 week, 1 month, 2 months, 3 months, and 6 months, in accordance with the World Glaucoma Association's Guideline [25]. Refractive data were collected 4 weeks postoperatively. The postoperative medication dose was increased if there was a clinical judgment that the IOP level would likely cause progression of glaucoma. In general, glaucoma medication was started if IOP exceeded $18 \mathrm{mmHg}$, because the Advanced Glaucoma Intervention Study (AGIS) demonstrated that progression was delayed when IOP was maintained below $18 \mathrm{mmHg}$ [4].

\section{Data Analysis}

Surgical successes based on IOP control were defined according to three criteria: (A) IOP $<15 \mathrm{mmHg}$ without medication; (B) IOP $<18 \mathrm{mmHg}$ without medication; and (C) IOP $<18 \mathrm{mmHg}$ with or without medication. Fixed combination medications were reported as two medications.

The spherical equivalent (SE) refractive outcome was calculated as the difference between the postoperative SE and target SE and divided into the percentage within $0.25,0.50$, and $1.00 \mathrm{D}$ of the target. Astigmatism outcomes were measured using the American Society of Cataract and Refractive Surgery Astigmatism Double Angle Plot Tool version 1.3.2 [26]. This tool was used to analyze preoperative corneal astigmatism and postoperative refractive astigmatism (https://ascrs.org/tools/astigmatismdouble-angle-plot-tool).

The sample size calculation (non-inferiority, dichotomous outcomes) was confirmed on the basis of the following assumptions: type I error rate, $\alpha=0.05$; power, $1-\beta=0.80$; ratio of case to control, $1: 3$; drop rate $=10 \%$; proportion of the outcome (SE from target $<1 \mathrm{D}$ ) in the control group $=0.85$ (considering The National Health Service data) $[27,28]$; and margin on risk difference scale $=0.20$. As a result, calculated sample sizes were 33 cases and 99 controls.

Statistical analyses were performed using SPSS for Windows software (version 18.0, SPSS Inc., Chicago, IL). A paired $t$ test was used to determine the significance of the mean change in IOP from baseline to 1,3 , and 6 months. Independent $t$ tests and chi-square tests were used to compare the control group. $P<0.05$ was defined as statistical significance.

\section{RESULTS}

\section{Baseline Characteristics}

A total of 36 eyes from 36 patients with openangle glaucoma who underwent concomitant cataract surgery with two iStent ${ }^{\circledR}$ inject were analyzed retrospectively. Four of the initially enrolled 40 eyes were excluded: two eyes with missing postoperative refraction and two eyes with suboptimal implantation (one eye with under-implantation, one eye with over-implantation). We excluded the suboptimal cases to minimize the confounding factors (corneal properties, refractive outcomes, and IOP). Table 1 summarizes the demographic data of the participants. The mean age was $74.4 \pm 4.1$ years in the combination group and $73.9 \pm 4.9$ years in the control group $(P=0.554)$. Preoperative baseline IOP was $15.1 \pm 2.9 \mathrm{mmHg}$ on $1.9 \pm 1.0$ glaucoma medications in the combination group and $14.3 \pm 2.7 \mathrm{mmHg}$ on no glaucoma medication in the control group $(P=0.132)$. Most of the participants in the combination group had mild-to-moderate OAG, and the remaining eight eyes $(22.2 \%)$ had severe disease. Two eyes had previously undergone selective laser trabeculoplasty (SLT). None of the patients in the treatment group had previously undergone incisional glaucoma surgery. 
Table 1 Demographic and baseline patient characteristics

\begin{tabular}{|c|c|c|c|}
\hline & $\begin{array}{l}\text { Combination group }(N=36) \\
\text { Trabecular microbypass stents (iStent } ® \text { inject) with } \\
\text { cataract extraction }\end{array}$ & $\begin{array}{l}\text { Control group } \\
(N=100) \\
\text { Phacoemulsification } \\
\text { alone }\end{array}$ & $P$ value \\
\hline Age (years) & $74.4 \pm 4.1$ & $73.9 \pm 4.9$ & 0.554 \\
\hline Eye (right/left) & $18 / 18$ & $48 / 52$ & 0.848 \\
\hline Preoperative IOP & $15.1 \pm 2.9 \mathrm{mmHg}$ & $14.3 \pm 2.7 \mathrm{mmHg}$ & 0.132 \\
\hline \multicolumn{4}{|l|}{ Proportion of preoperative IOP } \\
\hline$<15 \mathrm{mmHg}$ & $20(55.6 \%)$ & $59(59.0 \%)$ & 0.844 \\
\hline$<18 \mathrm{mmHg}$ & $28(77.8 \%)$ & $85(85.0 \%)$ & 0.314 \\
\hline$<21 \mathrm{mmHg}$ & $36(100 \%)$ & $100(100.0 \%)$ & 1.000 \\
\hline \multicolumn{4}{|l|}{ Visual field } \\
\hline Mean deviation $(\mathrm{dB})$ & $-8.67 \pm 6.67($ range $0.48-25.00)$ & NA & \\
\hline $\begin{array}{l}\text { Pattern standard deviation } \\
(\mathrm{dB})\end{array}$ & $6.41 \pm 3.41($ range $1.98-13.09)$ & NA & \\
\hline Visual field index (VFI, \%) & $76.90 \pm 22.33($ range $23-98)$ & NA & \\
\hline \multicolumn{4}{|l|}{ Optical coherence tomography } \\
\hline $\begin{array}{l}\text { Retinal nerve fiber layer } \\
\text { thickness }(\mu \mathrm{m})\end{array}$ & $73.47 \pm 12.75($ range $48-101)$ & NA & \\
\hline Vertical cup-to-disc ratio & $0.79 \pm 0.09($ range $0.61-0.94)$ & NA & \\
\hline \multicolumn{4}{|l|}{ Glaucoma stage } \\
\hline Early & $15(41.7 \%)$ & NA & \\
\hline Moderate & $13(36.1 \%)$ & NA & \\
\hline Advanced & $8(22.2 \%)$ & NA & \\
\hline
\end{tabular}

Values in the table are presented as mean \pm standard deviation (SD) or as a percentage IOP intraocular pressure, $N A$ Not applicable

\section{Intraocular Pressure Reduction}

In the combination group, significant IOP reduction was observed at postoperative 1 week, 1 month, 3 months, and 6 months compared to the preoperative baseline IOP. Compared to the baseline mean IOP $(15.1 \pm 2.9 \mathrm{mmHg})$, the mean IOP reduction was $13.5 \pm 4.2 \mathrm{mmHg}$ at 1 week, $\quad 12.6 \pm 3.0 \mathrm{mmHg}$ at 1 month, $12.2 \pm 2.4 \mathrm{mmHg}$ at 3 months, and $12.5 \pm 2.0 \mathrm{mmHg}$ at 6 months in the combination group $(P=0.011, \quad P<0.001$, $P<0.001, P<0.001$, respectively). Regarding hypotensive medication use, statistically significant reductions were found during the entire study period (all $P<0.001$ ). In summary, IOP decreased by $2.6 \mathrm{mmHg}(17.2 \%)$ at 6 months and the mean number of medications decreased from $1.9 \pm 1.0$ to $0.4 \pm 0.9$ at 1 month, $0.3 \pm 0.8$ at 3 months, and $0.4 \pm 0.9$ at 6 months in the combination group. These results are summarized in Fig. 1. The mean IOP 


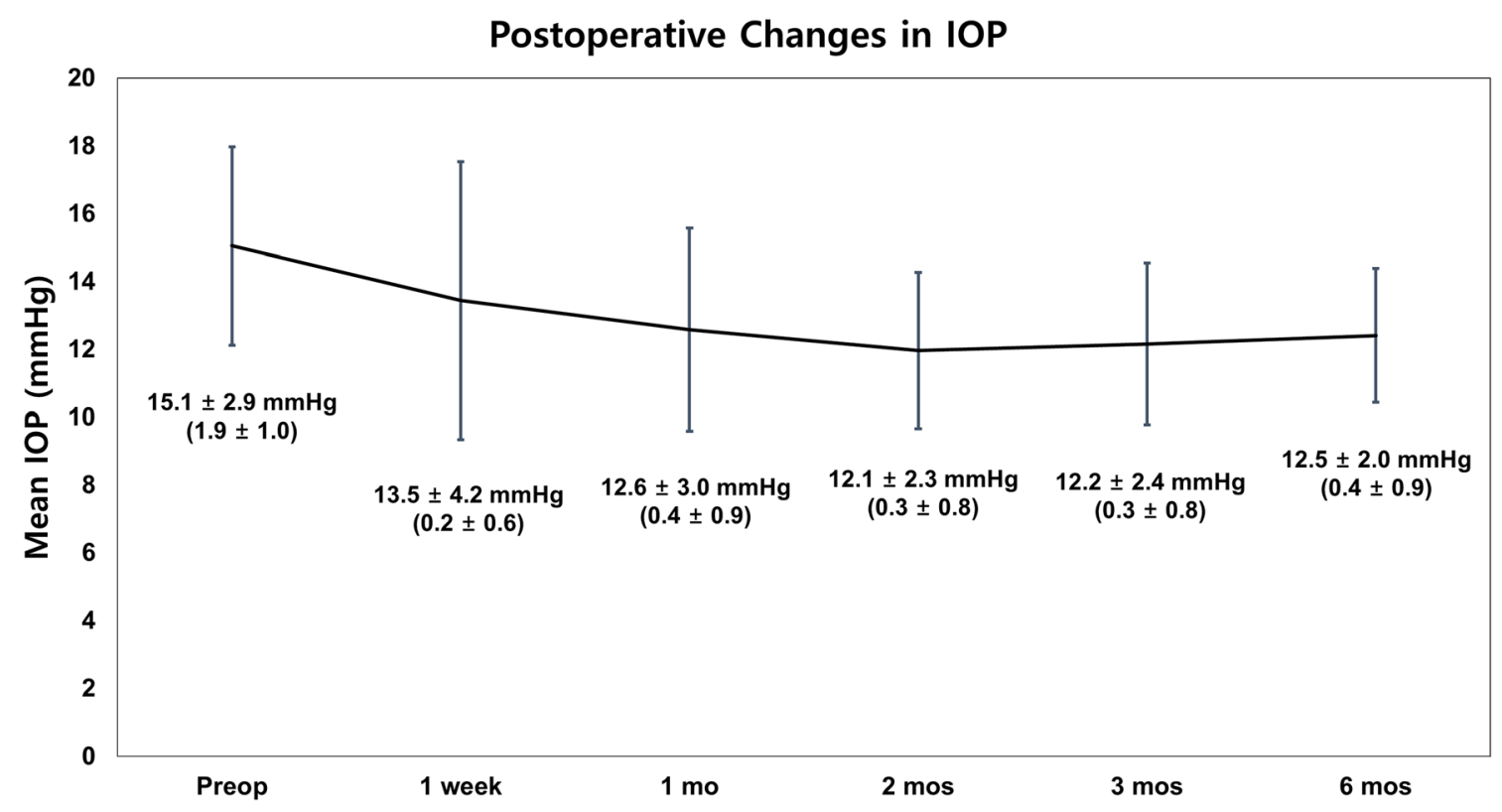

Fig. 1 Postoperative changes in intraocular pressure in the combination group. Following the combination procedure, trabecular microbypass stents (iStent ${ }^{\circledR}$ inject) with phacoemulsification, mean intraocular pressure (IOP), and number of medications decreased significantly and were maintained during the study period. Participant IOP

was $\quad 14.3 \pm 2.7 \mathrm{mmHg}$ at baseline, $13.3 \pm 3.0 \mathrm{mmHg}$ at 1 week, and $13.1 \pm 2.1 \mathrm{mmHg}$ at 1 month in the control group $(P<0.001, P<0.001$, respectively).

\section{Proportional Analysis of IOP Reduction}

A greater proportion of eyes with lower IOP at follow-up vs. baseline was observed in the combination group (Fig. 2). The proportion of patients was $77.8 \%$ for criterion A (versus $55.6 \%$ of patients with preoperative IOP $<15 \mathrm{mmHg}$, $P=0.046$ ), $83.3 \%$ for criterion B (versus $77.8 \%$ with preoperative IOP $<18 \mathrm{mmHg}, P=0.551$ ), and $97.2 \%$ for criterion $C$ (versus $77.8 \%$ with preoperative $\quad$ IOP $<18 \mathrm{mmHg}, \quad P=0.028$ ). Moreover, $83.3 \%$ of the combination patients were medication-free at 6 months.

\section{Refractive Outcome}

The corrected distance visual acuity (CDVA) significantly improved from decreased from $15.1 \pm 2.9 \mathrm{mmHg}$ on $1.9 \pm 1.0$ medications to $12.4 \pm 2.0 \mathrm{mmHg}$ on $0.4 \pm 0.8$ medications at postoperative 6 months $\quad(P<0.001, \quad P<0.001$, respectively)

$0.47 \pm 0.21 \log$ MAR to $0.06 \pm 0.07 \log$ MAR at 1 month in the combination group $(P<0.001)$. Mean error is an unreliable value because it can be positive or negative values and, therefore, might be affected by outliers. Thus, we used the mean absolute error (MAE) from a refractive target. Regarding MAE from a refractive target using spherical equivalent (SE) outcomes, $44.4 \%$ (16 of 36 eyes) had SEs within $0.25 \mathrm{D}$ (47\% in the control group, $P=0.792$ ), $83.3 \%$ had SEs within $0.50 \mathrm{D}(76 \%$ in the control group, $P=0.363$ ), and $97.2 \%$ had SEs within $1.00 \mathrm{D}$ of the target (97\% in the control group, $P=1.000)$. The MAE was $0.33 \pm 0.26 \mathrm{D}$ in the combination group and $0.38 \pm 0.33 \mathrm{D}$ in the control group $(P=0.309)$.

Figure 3 shows the magnitude of preoperative corneal astigmatism and postoperative refractive astigmatism. For magnitude of astigmatism at postoperative 1 month, $64 \%$ of participants were within $1.00 \mathrm{D}, 83 \%$ in $1.5 \mathrm{D}$, and $94 \%$ within $2.0 \mathrm{D}$ in the combination group compared to $70 \%, 86 \%$, and $99 \%$, respectively, 


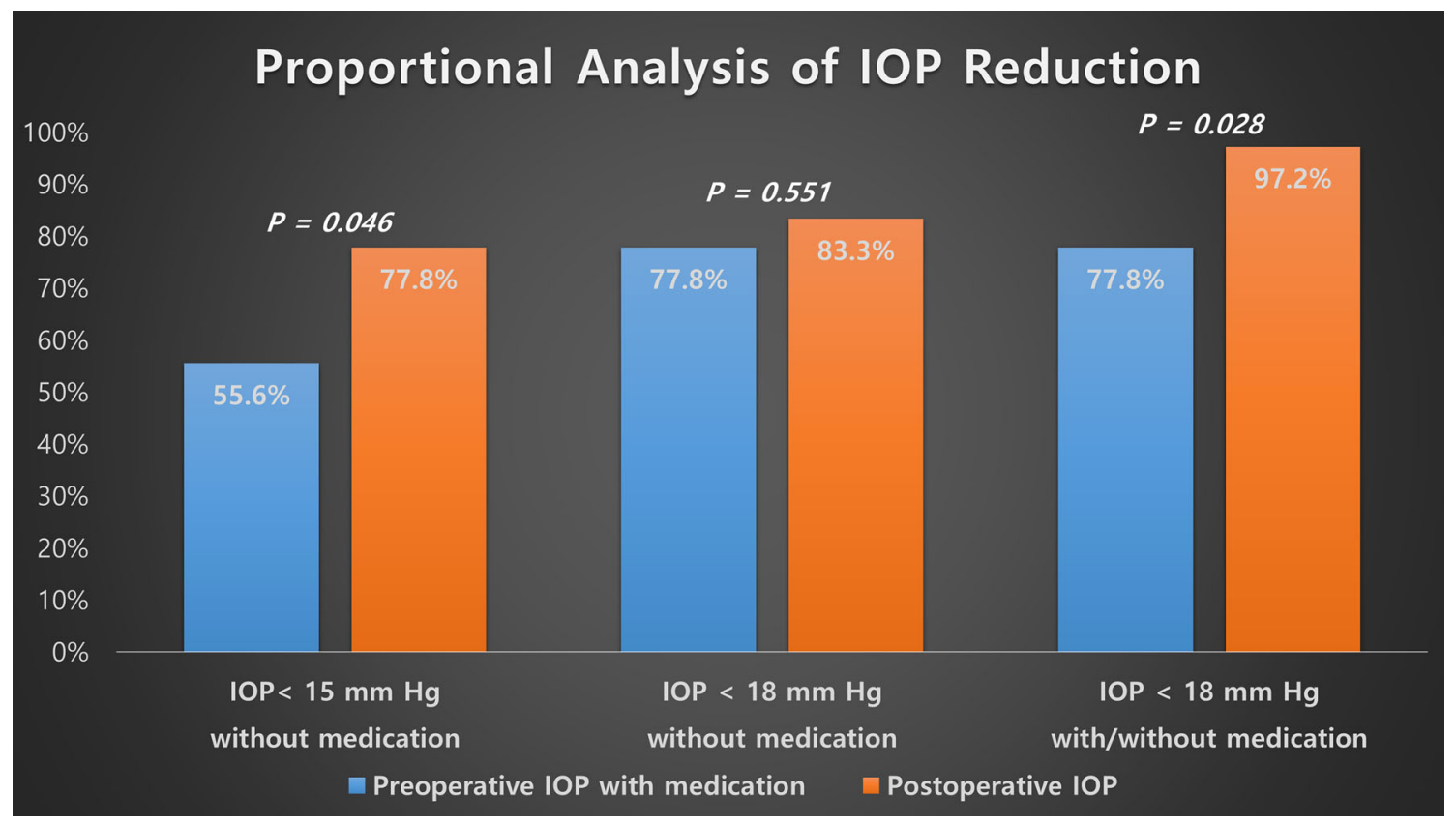

Fig. 2 Proportional analysis of IOP reduction in the combination group. Figure shows the percentage of eyes with IOP $<15 \mathrm{mmHg}$ without medication, IOP $<18 \mathrm{mmHg}$ without medication, and IOP $<18 \mathrm{mmHg}$ with or without medication compared

in the control group. There were no significant differences between the combination and control groups $(P=0.328,0.652$, and 0.111, respectively).

Figure 4 demonstrates the double-angle plot showing the preoperative and postoperative astigmatic vectors. The preoperative centroid was $0.51 \mathrm{D}$ at $168^{\circ}$ with a mean absolute $1.02 \pm 0.66 \mathrm{D}$, and the postoperative centroid was $0.66 \mathrm{D}$ at $178^{\circ}$ with a mean absolute $1.06 \pm 0.54 \mathrm{D}$ in the combination group. The preoperative centroid was $0.23 \mathrm{D}$ at $176^{\circ}$ with a mean absolute $0.85 \pm 0.49 \mathrm{D}$, and the postoperative centroid was $0.66 \mathrm{D}$ at $1^{\circ}$ with a mean absolute $0.97 \pm 0.81 \mathrm{D}$ in the control group. There were no statistical significant differences between the two groups with respect to preoperative mean absolute and postoperative mean absolute. $(P=0.164, P=0.322$, respectively). to the percentage of eyes with baseline preoperative IOP with medication $<15 \mathrm{mmHg}$ or $<18 \mathrm{mmHg}$ $(P=0.046, P=0.551, P=0.028$, respectively; Fisher's exact test and chi-square test)

\section{Safety}

There were no severe intraoperative complications that required additional procedures. The most frequently reported side effects were hyphema in three eyes (8.3\%) and transient IOP spike (IOP $>25 \mathrm{mmHg}$ ) in two eyes $(5.6 \%$ ) within the first week. No vision-threatening adverse events, such as endophthalmitis, hypotony, choroidal detachment, or corneal decompensation, occurred.

\section{DISCUSSION}

In the present study, the combination of two second-generation trabecular microbypass stents (iStent ${ }^{\circledR}$ inject) and phacoemulsification demonstrated favorable IOP control, including mean IOP reduction and a significant decrease in number of medications. Our study showed a mean IOP reduction of $2.6 \mathrm{~mm} \mathrm{Hg} \mathrm{(17.2 \% )} \mathrm{at}$ month 6 without washout periods. Furthermore 
a

$$
N=36
$$

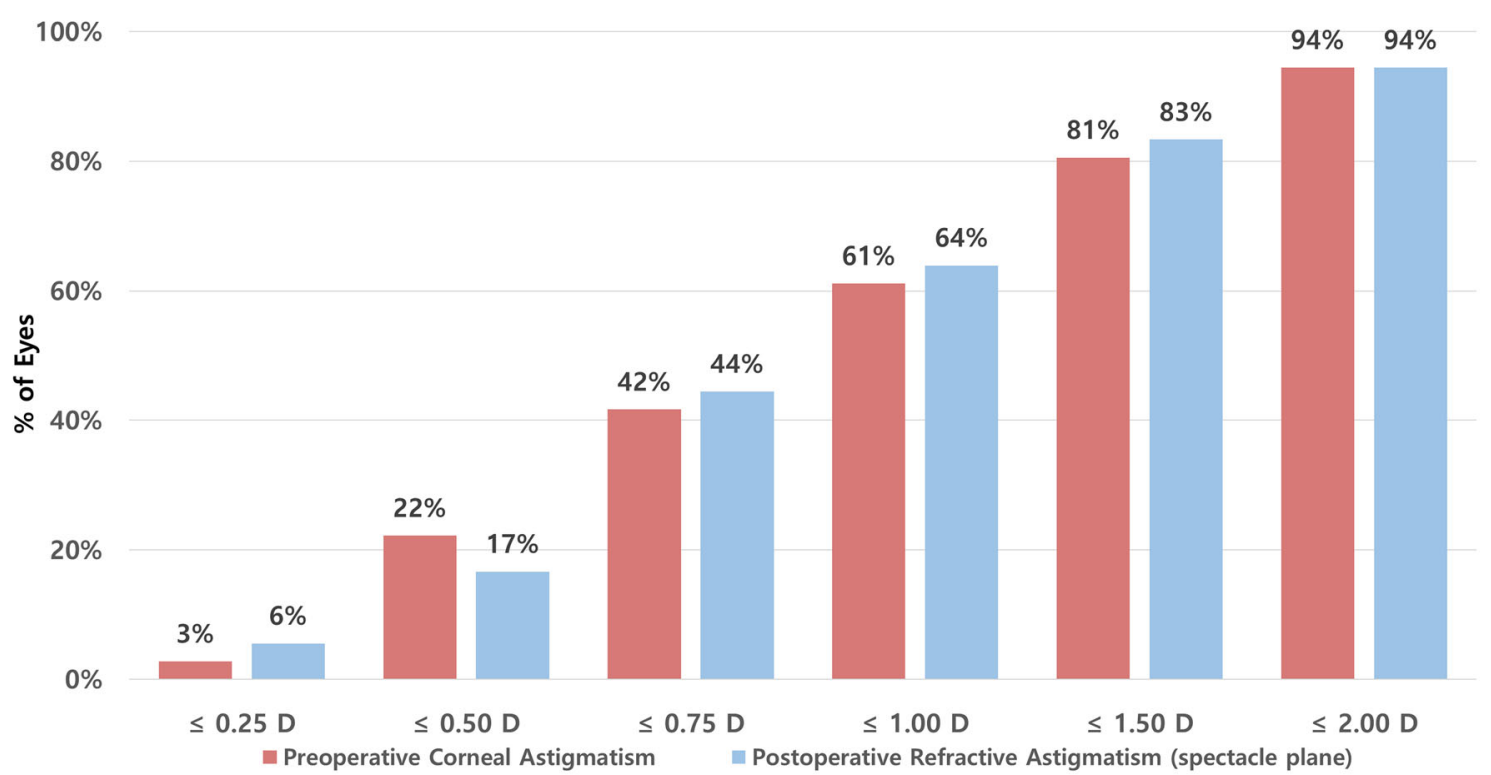

b
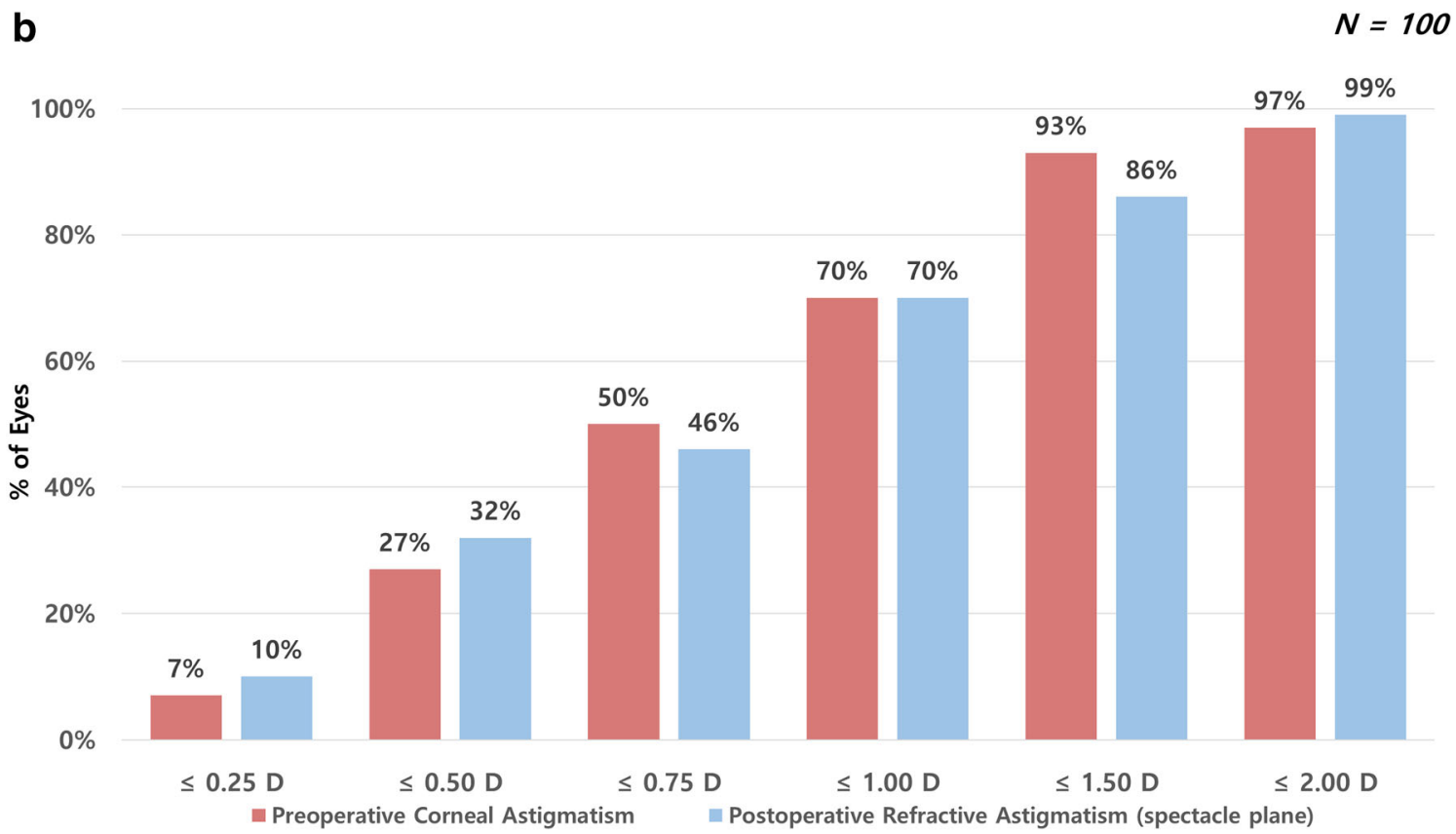

Fig. 3 Magnitude of preoperative corneal astigmatism and postoperative refractive astigmatism in eyes with trabecular microbypass stent (iStent ${ }^{\circledR}$ inject) implantation with American Society of Cataract and Refractive Surgery's Astigmatism Double Angle Plot Tool version 1.3.2 cataract extraction (a) and control group (b) using the

$77.8 \%$ of eyes maintained an IOP $<15 \mathrm{mmHg}$, and $83.3 \%$ of eyes maintained an IOP $<18 \mathrm{mmHg}$ without medication. A total of
$97.2 \%$ of eyes had an IOP $<18 \mathrm{mmHg}$ with or without medication. Moreover, $83.3 \%$ of eyes were medication-free (all medication was 


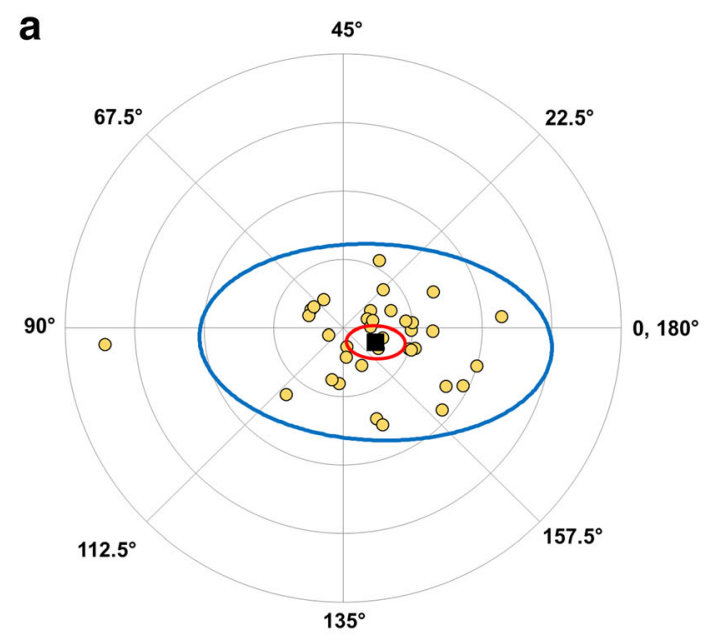

Centroid : 0.51D@ 168 $\pm 1.12 \mathrm{D}$

Mean Absolute: $1.02 D \pm 0.66 D$

Centroid $\bigcirc 95 \%$ confidence ellipse of the centroid

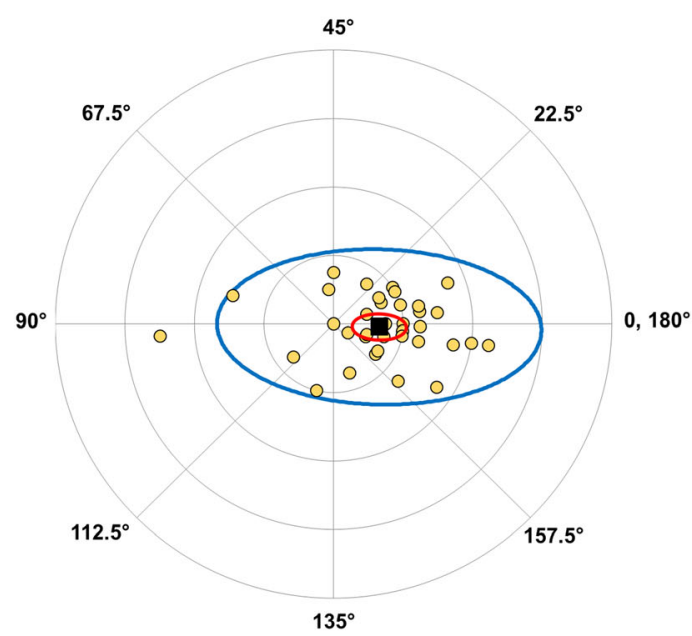

Centroid : 0.66D@ 178 $\pm 1.00 \mathrm{D}$

Mean Absolute: $\quad 1.06 D \pm 0.54 D$

$N=36$ b

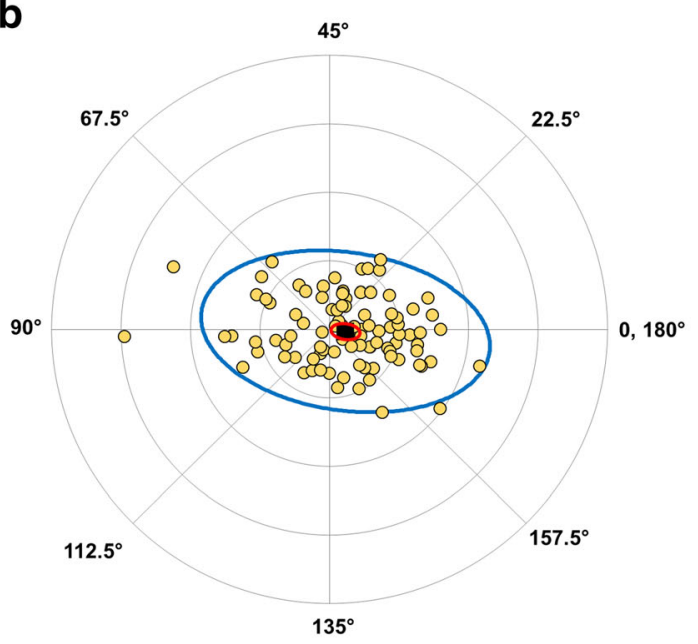

Centroid : $0.23 \mathrm{D} @ 176^{\circ} \pm 0.96 \mathrm{D}$

Mean Absolute: $\quad 0.85 D \pm 0.49 D$

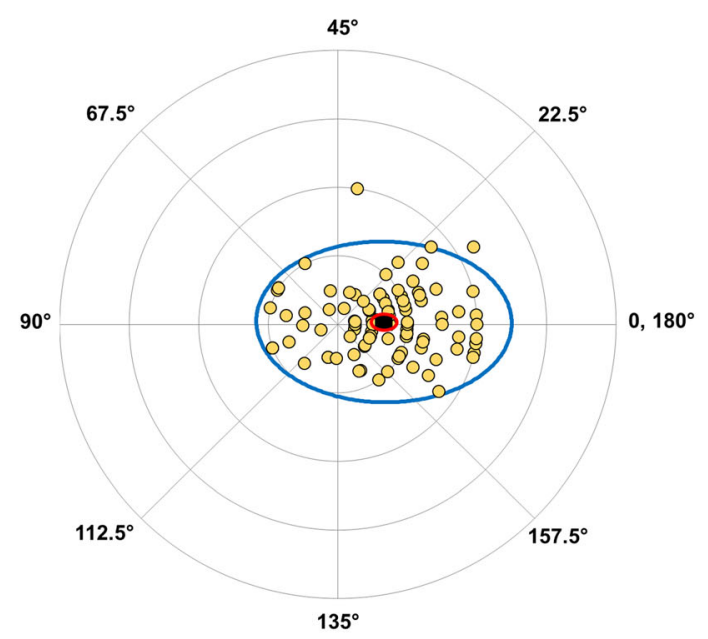

Centroid: 0.66D@ $1^{\circ} \pm \mathbf{0 . 8 7 D}$

Mean Absolute: $\quad 0.97 D \pm 0.51 D$
$N=100$
Fig. 4 Double-angle plot showing preoperative and postoperative astigmatic vectors, mean, and spread in eyes with trabecular microbypass stent (iStent ${ }^{\circledR}$ inject) implantation with cataract extraction (a) and in the control group

eliminated). These results were similar to those of previous studies.

Guedes and Gravina [12] reported that mean IOP decreased from $17.3 \pm 3.0 \mathrm{mmHg}$ on 2.3 medications to $12.7 \pm 1.8 \mathrm{mmHg}$ on 0.4 (b) using the American Society of Cataract and Refractive Surgery's Astigmatism Double Angle Plot Tool version 1.3.2

medications in those with the iStent ${ }^{\circledR}$ inject at 6 months. In their study, proportional analysis showed that the percentage of eyes with IOP $<18 \mathrm{mmHg}$, $<16 \mathrm{mmHg}$, and $<14 \mathrm{mmHg}$ was $100.0 \%, 88.6 \%$, and $71.4 \%$, respectively. 
Manning reported IOP reduction from $20.4 \pm 5.6 \mathrm{mmHg}$ on $1.3 \pm 0.9$ medications to $14.1 \pm 2.1 \mathrm{mmHg}$ on $0.1 \pm 0.3$ medications. He also observed $92.5 \%$ of patients had IOP $\leq 18 \mathrm{mmHg}$, and $71.6 \%$ of patients had IOP $\leq 15 \mathrm{mmHg}$ at 12 months [16]. Our baseline IOP $(15.1 \mathrm{mmHg})$ was somewhat lower than that reported in the aforementioned studies (17.3 and $20.4 \mathrm{~mm} \mathrm{Hg}$, respectively) because we only included eyes with preoperative IOP less than $21 \mathrm{mmHg}$ with medication, and Asian eyes involve a higher proportion of normal-tension glaucoma. Given the wellknown pattern of less dramatic IOP reduction in eyes with lower baseline IOP, our result that IOP reduction was less than in previous studies of iStent ${ }^{\circledR}$ inject with phacoemulsification in patients with predominantly high-tension primary open-angle glaucoma (POAG) is reasonable. Most previous studies regarding the efficacy of iStent implant of iStent ${ }^{\circledR}$ inject included patients with uncontrolled IOP or mean medicated IOP above $21 \mathrm{mmHg}$, and there are limited studies on outcomes in controlled glaucoma [10, 11, 13, 17]. The majority of open-angle glaucoma cases in Korea and Japan are low-tension or normal-tension glaucoma. To the best of our knowledge, the present study is the first study that describes the clinical efficacy (IOP-lowering effect and refractive changes) of iStent ${ }^{\circledR}$ inject in a South Korean population. Thus, our results have strength in management of glaucoma in subjects in EastAsians, who are considered to have lower baseline IOP with or without medications compared to other populations.

Considering these factors, our results are similar to the study by Salimi and colleagues [13]. In their 1-year multicenter study, they reported that postoperative IOP declined by $22 \%$ from $15.8 \mathrm{mmHg}$ on $1.5 \pm 1.28$ medications to $12.3 \mathrm{mmHg}$ on $0.4 \pm 0.86$ medications [13]. They also reported that all eyes (100\%) measured $\leq 18 \mathrm{mmHg}$ postoperatively (versus $74 \%$ preoperatively), and $92 \%$ had IOP $\leq 15 \mathrm{mmHg}$. In addition, $73 \%$ of the eyes were medication-free at 1 year. In summary, the results from previous studies and the present study demonstrated a significant reduction in medication use, and a significant proportion of patients ceased their medication after combination procedures $[12,13,18]$. These results are valuable in the context of disease progression, quality of life, secondary ocular surface disease, medication costs, and psychological aspects $[9,10,15,23]$.

The refractive impact of MIGS-associated phacoemulsification (combination procedure) is expected to be minimal; however, there are a limited number of studies on refractive outcomes [9]. Regarding spherical equivalent (SE) outcomes, 44.4\% had SEs within 0.25 D, 83.3\% had SEs within $0.50 \mathrm{D}$, and $97.2 \%$ had SEs within $1.00 \mathrm{D}$ of the target in combination group in our data. There was no statistical difference between the combination and control groups $(P=0.792, P=0.363$, and $P=1.000$, respectively). Our results are favorable and similar to those of previous studies regarding phaco-iStent ${ }^{\circledR}$ inject and those of a large cohort registry in standard cataract surgery. Scott et al. reported $80 \%$ and $95 \%$ of eyes within $0.50 \mathrm{D}$ and $1.00 \mathrm{D}$, respectively, after iStent ${ }^{\circledR}$ implant and cataract surgery [9]. Recently, Ioannidis et al. reported that $73.8 \%$ of eyes had SEs $\leq 0.50 \mathrm{D}$ and $98.9 \%$ of eyes had SEs $\leq 1.00 \mathrm{D}$ [23]. The National Health Service data suggested a benchmark standard of $55 \%$ within $0.50 \mathrm{D}$ and $85 \%$ within $1.00 \mathrm{D} ; 62.3 \%$ of patients within $0.50 \mathrm{D}$ of the refractive target should represent a minimum level of efficiency following cataract surgery [27, 28]. MAE was $0.33 \pm 0.26 \mathrm{D}$ in our results, a finding similar to that of Ioannidis et al. $(0.36 \pm 0.25 \mathrm{D})$ [23].

For the magnitude of astigmatism at postoperative 1 month, there were no statistical significant differences in the proportions of $\leq 1.00 \mathrm{D}$, $\leq 1.50 \mathrm{D}$, and $\leq 2.00 \mathrm{D}$ between both groups (all $P$ values $>0.05$ ). Moreover, the double-angle plot demonstrated that the postoperative centroid in the combination group was similar to that in the control group (centroid, $0.66 @ 178^{\circ} \pm 1.00 \mathrm{D}$ vs.0.66 D @ $1^{\circ} \pm 0.87 \mathrm{D}$; mean absolute, $1.06 \pm 0.54$ vs. $0.97 \pm 0.51 \mathrm{D}, P=0.322$ ). These results were similar to those of a previous phaco-iStent ${ }^{\circledR}$ implant study by Scott et al. (75\% within $1.00 \mathrm{D}, 87 \%$ within $1.50 \mathrm{D}, 89 \%$ within $2.00 \mathrm{D}$; centroid, $0.8 \mathrm{D} @ 92^{\circ} \pm 1.05 \mathrm{D}$; mean absolute, 0.8 D) [9]. Moreover, our results demonstrate 
that the difference between preoperative centroid and postoperative centroid was not clinically significant in the combination group $\left(0.51 \mathrm{D} @ 168^{\circ} \pm 1.12 \mathrm{D}\right.$ vs. 0.66 @ $\left.178^{\circ} \pm 1.00 \mathrm{D}\right)$.

Because astigmatism has both magnitude and direction, and the analysis is complicated [29], there are two widely used categories of information: (1) certain scalar values: mean \pm SD, independent of angle, and percentages of eyes within certain ranges; and (2) vector analysis. However, vector of astigmatism is actually bidirectional because the axis or meridian is made up of two semi-meridians $[29,30]$. As a result, certain univariate analyses of astigmatism are unpredictably erroneous and misleading. In these contexts, recommended vector analyses should include double-angle plots with centroids and confidence ellipse of preoperative and postoperative astigmatism, along with means and standard deviations of these vector magnitudes [30]. Considering this background, we analyzed (1) the mean absolute error, (2) proportion within certain ranges, and (3) double-angle plot analysis.

The results of this study suggest that combination procedures-iStent ${ }^{\circledR}$ inject with phacoemulsification-are a good option in maintaining refractive outcomes with minimal risks for unanticipated refractive surprise. Our results add to the literature supporting the minimal impact of MIGS devices on refractive outcomes and surgically induced astigmatism effects $[9,10,23]$.

This study had some limitations. First, there was no washout period because of the retrospective design. We could not explain the exact proportion of normal-tension glaucoma because most patients were referred with glaucoma medications and we could not compare the long-term IOP changes in both groups. Thus, the "case-control" aspect of this study was limited on refractive outcomes. Second, cataract surgery itself could strengthen the IOP-lowering efficacy as observed in the Ocular Hypertension Treatment Study (OHTS) study [31]. Third, the study had a small sample size. Despite these drawbacks, this is the first study evaluating IOPlowering efficacy and refractive outcomes in Korean eyes. Despite the lack of a washout period, the results represent real-world clinical outcomes [12]. Moreover, Baek and colleagues reported a mean IOP reduction of $0.78 \mathrm{mmHg}$ at 1 year after cataract surgery in patients with normal tension glaucoma, suggesting that the IOP-lowering effects of cataract surgery itself might be limited in low-tension or medically controlled glaucoma given that eyes in this study showed a greater IOP response with iStent inject [32]. Future prospective studies with larger sample sizes would be valuable to confirm our results.

\section{CONCLUSIONS}

Combination procedures with second-generation trabecular microbypass stents seem to be effective in lowering IOP and do not compromise refractive outcomes. On the basis of our favorable results using Korean real-world clinical data, combination procedures have modest IOP-lowering effect and ability to reduce the glaucoma drug burden with no serious complications, and minimally impact the refractive outcome in patients with medically controlled glaucoma and coexisting cataracts.

\section{ACKNOWLEDGEMENTS}

The authors wish to thank the participants of the study.

Funding. This study was supported by a VHS Medical Center research grant, Republic of Korea (Grant number, VHSMC 21003; Recipient, Su-Ho Lim). The journal's Rapid Service Fees were funded by Glaukos Corporation. Dr. Su-Ho Lim had full access to all of the data in this study and takes complete responsibility for the integrity of the data and accuracy of the data analysis. The funders had no role in study design, data collection and analysis, or preparation of the manuscript. The patients were seen as part of Dr. Lim's glaucoma clinical service practice.

Medial Writing and Editorial Assistance. The authors wish to thank 
eWorldEditing and PaperPal PreFlight service for language editing.

Authorship. All named authors meet the International Committee of Medical Journal Editors (ICMJE) criteria for authorship of this article, take responsibility for the integrity of the work as a whole, and have given their approval for this version to be published.

Author Contributions. Conceptualization: Seungsoo Rho, Su-Ho Lim; Data curation: Seungsoo Rho, Su-Ho Lim; Funding acquisition: Su-Ho Lim; Resources: Su-Ho Lim; Writingoriginal draft: Su-Ho Lim; Writing-review and editing: Seungsoo Rho, Su-Ho Lim.

Disclosures. This study was supported by a VHS Medical Center research grant, Republic of Korea (Grant number, VHSMC 21003; Recipient, Su-Ho Lim). The funders had no role in study design, data collection and analysis, or preparation of the manuscript. Seungsoo Rho and Su-Ho Lim declare that they have no conflict of interests to declare.

Compliance with Ethics Guidelines. The study protocol was approved by the Institutional Review Board of Daegu Veterans Health Service Medical Center. All participants provided signed informed consent, and this study adhered to the tenets of the 1964 Declaration of Helsinki.

Data Availability. The datasets generated and/or analyzed during the current study are available from the corresponding author on reasonable request.

Open Access. This article is licensed under a Creative Commons Attribution-NonCommercial 4.0 International License, which permits any non-commercial use, sharing, adaptation, distribution and reproduction in any medium or format, as long as you give appropriate credit to the original author(s) and the source, provide a link to the Creative Commons licence, and indicate if changes were made. The images or other third party material in this article are included in the article's Creative Commons licence, unless indicated otherwise in a credit line to the material. If material is not included in the article's Creative Commons licence and your intended use is not permitted by statutory regulation or exceeds the permitted use, you will need to obtain permission directly from the copyright holder. To view a copy of this licence, visit http:// creativecommons.org/licenses/by-nc/4.0/.

\section{REFERENCES}

1. Quigley HA, Broman AT. The number of people with glaucoma worldwide in 2010 and 2020. Br J Ophthalmol. 2006;90(3):262-7.

2. Leske MC, Heijl A, Hyman L, Bengtsson B, Komaroff E. Factors for progression and glaucoma treatment: the Early Manifest Glaucoma Trial. Curr Opin Ophthalmol. 2004;15(2):102-6.

3. Collaborative Normal-Tension Glaucoma Study Group. Comparison of glaucomatous progression between untreated patients with normal-tension glaucoma and patients with therapeutically reduced intraocular pressures. Am J Ophthalmol. 1998;126(4):487-97.

4. The AGIS Investigators. The Advanced Glaucoma Intervention Study (AGIS): 7. The relationship between control of intraocular pressure and visual field deterioration. Am J Ophthalmol. 2000;130(4): 429-40.

5. Gedde SJ, Feuer WJ, Lim KS, et al. Treatment outcomes in the primary tube versus trabeculectomy study after 3 years of follow-up. Ophthalmology. 2020;127(3):333-45.

6. Vinod K, Gedde SJ. Safety profile of minimally invasive glaucoma surgery. Curr Opin Ophthalmol. 2021;32(2):160-8.

7. Budenz DL, Feuer WJ, Barton K, et al. Postoperative complications in the Ahmed Baerveldt comparison study during five years of follow-up. Am J Ophthalmol. 2016;163:75-82 e3.

8. European Glaucoma Society. European Glaucoma Society terminology and guidelines for glaucoma, 4th edition - Chapter 2: Classification and terminology supported by the EGS Foundation. $\mathrm{Br} \mathrm{J}$ Ophthalmol. 2017;101:73-127.

9. Scott RA, Ferguson TJ, Stephens JD, Berdahl JP. Refractive outcomes after trabecular microbypass stent with cataract extraction in open-angle glaucoma. Clin Ophthalmol. 2019;13:1331-40. 
10. Lavia C, Dallorto L, Maule M, Ceccarelli M, Fea AM. Minimally-invasive glaucoma surgeries (MIGS) for open angle glaucoma: a systematic review and meta-analysis. PLoS One. 2017;12(8):e0183142.

11. Agrawal P, Bradshaw SE. Systematic literature review of clinical and economic outcomes of microinvasive glaucoma surgery (MIGS) in primary openangle glaucoma. Ophthalmol Ther. 2018;7(1): 49-73.

12. Guedes RAP, Gravina DM, Lake JC, Guedes VMP, Chaoubah A. Intermediate results of iStent or iStent inject implantation combined with cataract surgery in a real-world setting: a longitudinal retrospective study. Ophthalmol Ther. 2019;8(1):87-100.

13. Salimi A, Clement C, Shiu M, Harasymowycz P. Second-generation trabecular micro-bypass (iStent inject) with cataract surgery in eyes with normaltension glaucoma: one-year outcomes of a multicentre study. Ophthalmol Ther. 2020;9(3):585-96.

14. Salimi A, Watt H, Harasymowycz P. Three-year outcomes of second-generation trabecular microbypass stents (iStent inject) with phacoemulsification in various glaucoma subtypes and severities. J Glaucoma. 2021;30(3):266-75.

15. Singh IP, Sarkisian S, Hornbeak D, Katz LJ, Samuelson T, iStent inject Study G. Treatment success across different levels of preoperative disease burden: stratified two-year outcomes from the pivotal trial of iStent inject (®) trabecular microbypass in primary open-angle glaucoma and cataract. Clin Ophthalmol. 2021;15:3231-40.

16. Manning D. Real-world case series of iStent or iStent inject trabecular micro-bypass stents combined with cataract surgery. Ophthalmol Ther. 2019;8(4): 549-61.

17. Kim HJ, Lim SH. Clinical outcomes of trabecular microbypass stent (iStent) implantation in medically controlled open-angle glaucoma in the Korean population. Medicine (Baltimore). 2020;99(33): e21729.

18. Neuhann R, Neuhann T. Second-generation trabecular micro-bypass stent implantation: retrospective analysis after 12- and 24-month follow-up. Eye Vis (Lond). 2020;7:1.

19. Davids A-M, Pahlitzsch M, Boeker A, et al. iStent inject as a reasonable alternative procedure following failed trabeculectomy? Eur J Ophthalmol. 2018;28(6):735-40.

20. Francis BA, Wang $\mathrm{M}$, Lei $\mathrm{H}$, et al. Changes in axial length following trabeculectomy and glaucoma drainage device surgery. $\mathrm{Br} \mathrm{J}$ Ophthalmol. 2005;89(1):17-20.
21. Muallem MS, Nelson GA, Osmanovic S, Quinones $\mathrm{R}$, Viana M, Edward DP. Predicted refraction versus refraction outcome in cataract surgery after trabeculectomy. J Glaucoma. 2009;18(4):284-7.

22. El-Saied HM, Foad PH, Eldaly MA, Abdelhakim MA. Surgically induced astigmatism following glaucoma surgery in Egyptian patients. J Glaucoma. 2014;23(3):190-3.

23. Ioannidis AS, Toteberg-Harms M, Hamann T, Hodge C. Refractive outcomes after trabecular micro-bypass stents (iStent Inject) with cataract extraction in open-angle glaucoma. Clin Ophthalmol. 2020;14:517-24.

24. Hodapp E, Parrish RK, Anderson DR. Clinical decisions in glaucoma. St. Louis: Mosby; 1993.

25. Shaarawy T, Grehn F. Guidelines on design and reporting of glaucoma surgical trials. Amsterdam: Kugler; 2009.

26. Abulafia A, Koch DD, Holladay JT, Wang L, Hill W. Pursuing perfection in intraocular lens calculations: IV. Rethinking astigmatism analysis for intraocular lens-based surgery: suggested terminology, analysis, and standards for outcome reports. J Cataract Refract Surg. 2018;44(10):1169-74.

27. Gale RP, Saldana M, Johnston RL, Zuberbuhler B, McKibbin M. Benchmark standards for refractive outcomes after NHS cataract surgery. Eye (Lond). 2009;23(1):149-52.

28. Brogan K, Diaper CJM, Rotchford AP. Cataract surgery refractive outcomes: representative standards in a National Health Service setting. Br J Ophthalmol. 2019;103(4):539-43.

29. Reinstein DZ, Archer TJ, Randleman JB. JRS standard for reporting astigmatism outcomes of refractive surgery. Thorofare: SLACK; 2014.

30. Koch DD, Wang L, Abulafia A, Holladay JT, Hill W. Rethinking the optimal methods for vector analysis of astigmatism. J Cataract Refrac Surg. 2021;47(1): 100-5.

31. Mansberger SL, Gordon MO, Jampel $\mathrm{H}$, et al. Reduction in intraocular pressure after cataract extraction: the Ocular Hypertension Treatment Study. Ophthalmology. 2012;119(9):1826-31.

32. Baek SU, Kwon S, Park IW, Suh W. Effect of phacoemulsification on intraocular pressure in healthy subjects and glaucoma patients. J Korean Med Sci. 2019;34(6):e47. 